\title{
Inclusão de resíduo da cultura de sorgo em painéis aglomerados de eucalipto
}

\author{
José Benedito Guimarães Junior ${ }^{1}$, Michele Mantelli Xavier ${ }^{2}$, Thamara Silva Santos ${ }^{2}$, Thiago de Paula Protásio ${ }^{1}$, \\ Rafael Farinassi Mendes ${ }^{1}$, Lourival Marin Mendes ${ }^{1}$
}

1Universidade Federal de Lavras, C P 3037, CEP 37200-000, Lavras, MG, Brasil

2Universidade Federal de Goiás, BR 364, Km 195, n. 3800, CEP 75801-615, Jataí, GO, Brasil

\section{"Autor correspondente:}

jbguimaraesjr@hotmail.com

Termos para indexação:

Resíduo agrícola

Lignocelulose

Propriedade mecânica

Index terms:

Agricultural waste

Lignocellulose

Mechanical properties

Histórico do artigo:

Recebido em 08/09/2015

Aprovado em 16/09/2016

Publicado em 30/12/2016

doi: 10.4336/2016.pfb.36.88.1036

\begin{abstract}
Resumo - O objetivo deste trabalho foi avaliar as qualidades físico-mecânicas de chapas aglomeradas de eucalipto produzidas com diferentes quantidades de resíduos da cultura de sorgo. Os painéis foram produzidos com 0, 15, 30 e 45\% de bagaço do sorgo e $12 \%$ do adesivo uréia-formaldeído. O ciclo de prensagem utilizado foi: pressão de 4,0MPa temperatura de $180^{\circ} \mathrm{C}$ por $20 \mathrm{~min}$. A qualidade das chapas foi avaliada por ensaios físico-mecânicos. Pelas avaliações físicas, todas as propriedades atenderam à norma CS 236-66, sendo que a cada $1 \%$ de sorgo acrescentado nos painéis, houve um aumento de 1,4 e 1,6\% na absorção de água, a 2 e 24 h de imersão, respectivamente. Para inchamento em espessura, após 2 e 24 h de imersão, não houve efeito significativo com o aumento na porcentagem de sorgo, porém apresentaram valor médio de IE24h apenas de $1,13 \%$ acima do exigido pela norma CS 236-66, que é 30\%. Em relação às propriedades mecânicas, pode-se constatar que o máximo de sorgo inserido nos painéis, para atendimento a norma CS 236-66, foi de $13 \%$.
\end{abstract}

\section{Addition of sorghum culture waste in eucalyptus particleboards}

\begin{abstract}
The objective of this study was to evaluate physical and mechanical properties of particleboard produced with different amounts of sorghum crop residues. The panels were made with $0,15,30$ and $45 \%$ of sorghum bagasse and $12 \%$ of ureaformaldehyde adhesive. The press cycle used was: $4,0 \mathrm{MPa}$ of pressure, $180{ }^{\circ} \mathrm{C}$ of temperature for $20 \mathrm{~min}$. To evaluate panels' quality physical and mechanical tests were carried out. Physical evaluations showed that all properties met the standard CS 236-66, and for every $1 \%$ of sorghum added on the panels there was an increase of 1.4 and $1.6 \%$ in water absorption at 2 and $24 \mathrm{~h}$ of immersion, respectively. For thickness swelling after 2 and $24 \mathrm{~h}$ of immersion there was no significant effect with increase in the percentage of sorghum, however it was observed an average value of IE24h only $1.13 \%$ higher than required by the standard CS 236-66 which is $30 \%$. Mechanical properties evaluation showed that $13 \%$ was maximum sorghum to be added in the panels to meet the standard CS 236-66.
\end{abstract}




\section{Introdução}

Painéis aglomerados são chapas provenientes de partículas de madeira ou materiais lignocelulósicos, coladas entre si com adesivo sintético (Moslemi, 1974; Tsoumis, 1991). De acordo com Guimarães Junior et al. (2011) os painéis aglomerados convencionais apresentam, por conceito, a possibilidade para utilização de matérias primas de menor qualidade, como resíduos florestais ou agroindustriais na sua produção.

De acordo com Mendes et al. (2010a), o consumo brasileiro por madeiras advindas de espécies florestais plantadas, especialmente as dos gêneros pinus e eucalipto, tem sido crescente. Para que haja atendimento a essa demanda há necessidade de se buscar novas matériasprimas que tenham alta produção e boa qualidade para tal finalidade. Neste sentido, o aproveitamento dos resíduos da agroindústria pode ser considerado uma alternativa para o setor de painéis aglomerados.

Dentre os resíduos com potencial para esta finalidade, destaca-se o sabugo de milho, casca de arroz, casca de café, casca de amendoim, pseudocaule de bananeira, casca de coco, caule de mandioca, casca de mamona, bagaço de cana, resíduo de soja, entre outros (Mendes et al., 2010a). De maneira geral, estes estudos apontam viabilidade de utilização de tais resíduos quando aplicados em associação com a madeira, mas que ainda requerem estudos quanto ao percentual de resíduo a ser inserido na chapa para atendimento das exigências normativas.

O agronegócio no sudoeste goiano é um dos mais expressivos nacionalmente, devido ao uso de tecnologia de ponta, com destaque para as culturas de soja, milho e sorgo. Entretanto, essa elevada produção acarreta geração de grande volume de resíduos ligonocelulósicos no meio rural, que normalmente são descartados ou queimados para a geração de energia, provocando a sua subutilização. Dados da Companhia Nacional de Abastecimento (2016) estimam que o Estado de Goiás gerou em 2015 aproximadamente 28 milhões de $t$ de resíduos referentes a culturas da soja, milho, cana, café, arroz e sorgo. Uma alternativa para agregação de valor a esses materiais lignocelulósicos seria sua utilização na fabricação de aglomerados, que levaria a um aproveitamento destes resíduos, contribuindo para um menor impacto ambiental da produção destes painéis, sem comprometimento na sua qualidade.

Dentre as diversas matérias-primas renováveis disponíveis no sudoeste goiano, destaca-se o sorgo granífero sacarino (Sorghum bicolor (L.) Moench). Essa cultura apresenta elevada produção de biomassa, açúcares fermentescíveis no caldo (Eggleston et al., 2013), amido nos grãos e celulose nos colmos, que podem ser convertidos em açúcares, após tratamento enzimático, antecedendo o processo fermentativo (Mussatto et al., 2010). Seu cultivo está ligado à produção de etanol e, como resíduo da cultura, tem-se o bagaço; que em alguns casos são queimados para geração de energia.

A produção de sorgo sacarino nacional, de acordo com dados da Companhia Nacional de Abastecimento (2015), na safra 2013/2014 foi de 1.891.200 t. Goiás foi o Estado com maior representação na produção, com 707,6 mil t. Estima-se que foi gerado, nesta safra, o equivalente a 775,3 mil t de bagaço de sorgo em todo Brasil, sendo que Goiás contribuiu com 290,11 mil t.

Neste sentido, o objetivo deste trabalho foi verificar o potencial de produção de painéis aglomerados a partir de madeira de eucalipto e do resíduo gerado pela cultura do sorgo sacarino.

\section{Material e métodos}

O material lignocelulósico utilizado para produção dos painéis foi bagaço da cultura de sorgo sacarino (Sorghum bicolor (L). Moench), obtidos através da empresa do ramo de energia Raízen, instalada em Jataí, GO. Também se utilizou madeira de eucalipto, proveniente de plantio experimental, com 36 meses de idade do híbrido Eucalyptus urophylla e Eucalyptus grandis, localizado no campus da Universidade Federal de Goiás, na Regional Jataí.

Para a determinação da densidade básica da madeira de eucalipto foram utilizadas as diretrizes da norma NBR 11941 (Associação Brasileira de Normas Técnicas, 2003). O cálculo da densidade básica das partículas de sorgo foi realizado segundo a mesma norma, com algumas adaptações na aferição do volume (deslocamento da água após adição das partículas de sorgo previamente saturadas, com auxilio de uma proveta graduada).

Para mensuração dos extrativos totais da madeira de eucalipto e resíduos de sorgo, estes tiveram suas dimensões reduzidas para, posteriormente, serem levados para o moinho e transformados em serragem. Após, foi feita separação em peneiras sobrepostas de 40 e 60 mesh, utilizando para análise somente a fração que ficou retida na peneira de 60 mesh. As amostras 
foram armazenadas em saco plástico e, posteriormente, determinados os valores de extrativos totais por meio da NBR 7987 T 204 om-88 (Associação Brasileira de Normas Técnicas, 1998).

Aplicou-se adesivo ureia-formaldeído na proporção de $12 \%$ em relação à massa seca de partículas. $\mathrm{O}$ adesivo apresentou as seguintes características: teor de sólidos de $56,87 \%$, pH de 8,45 , viscosidade de $460 \mathrm{cP}$ e tempo de gelatinizarão de $45 \mathrm{~s}$.

Para obtenção das partículas sliver da madeira de eucalipto, foi utilizado moinho do tipo martelo, e as partículas de sorgo foram obtidas por meio de moinho Willey. Ambas foram então peneiradas, sendo utilizada para produção dos painéis aquelas que ficaram retidas entre as peneiras de 10 e 30 mesh. Posteriormente, as partículas foram secas até umidade na base seca de $3 \%$.

Na sequência, as partículas de sorgo e madeira de eucalipto foram misturadas manualmente com adesivo uréia-formaldeído, não sendo usada emulsão de parafina. O colchão de partículas foi então pré-prensado a $0,5 \mathrm{MPa}$, por $5 \mathrm{~min}$, à temperatura ambiente. Posteriormente, o painel passou pelo ciclo de prensagem, com temperatura de $180^{\circ} \mathrm{C}$ e pressão específica de $4 \mathrm{MPa}$, por um período de 20 min, obtendo-se os painéis homogêneos.

Foram produzidos três painéis para cada tratamento utilizado, cujas dimensões nominais e a densidade foram, respectivamente, $200 \mathrm{~mm} \times \mathrm{x} 200 \mathrm{~mm} \times 15 \mathrm{~mm}$ e $0,60 \mathrm{~g} \mathrm{~cm}^{-3}$. Na Tabela 1 pode-se visualizar o delineamento utilizado.

Tabela 1. Delineamento experimental para produção dos painéis aglomerados.

\begin{tabular}{ccc}
\hline Tratamentos & Porcentagem de sorgo & $\begin{array}{c}\text { Porcentagem de } \\
\text { eucalipto }\end{array}$ \\
\hline T1 & 0 & 100 \\
T2 & 15 & 85 \\
T3 & 30 & 70 \\
T4 & 45 & 55 \\
\hline
\end{tabular}

A qualidade dos painéis foi avaliada pelas propriedades físicas de densidade, razão de compactação, absorção de água e inchamento em espessura e as propriedades mecânicas de tração perpendicular e flexão estática (módulo de elasticidade e módulo de ruptura). A razão de compactação foi calculada segundo Maloney (1993), onde se dividiu a densidade aparente do painel pela densidade aparente do material. A densidade aparente do material foi calculada multiplicando-se a porcentagem utilizada de cada material por sua respectiva densidade básica.
Para avaliação de absorção de água e inchamento em espessura após 2 e 24 h de imersão, flexão estática e tração perpendicular, retirou-se 4 corpos de prova por painel, para cada ensaio. De forma preliminar aos ensaios, os painéis foram climatizados à temperatura de $20 \pm 3{ }^{\circ} \mathrm{C}$ e umidade relativa de $65 \pm 5 \%$.

Utilizou-se o delineamento inteiramente casualizado, com 3 repetições, em que os tratamentos foram considerados as diferentes porcentagem de sorgo inseridas nos painéis. Utilizou-se regressão linear e quando esta não se apresentava significativa, utilizou-se o teste de Scott-Knott a 5\% de significância.

\section{Resultados e discussão}

\section{Caracterização dos materiais lignocelulósicos}

A densidade básica observada para o resíduo de sorgo foi $0,162 \mathrm{~g} \mathrm{~cm}^{-3}$, enquanto que para madeira de eucalipto foi encontrado valor médio de $0,393 \mathrm{~g} \mathrm{~cm}^{-3}$.

De acordo com a classificação do Instituto de Pesquisas Tecnológicas (1989) a densidade da madeira é considerada baixa quando menor que $0,500 \mathrm{~g} \mathrm{~cm}^{-3}$. Como não se tem uma classificação específica para materiais como sorgo, ao se comparar com a madeira, também se considera como densidade baixa. Iwakiri (2005) relata que a baixa densidade básica de materiais é um dos principais requisitos para a adaptabilidade dos materiais lignocelulósicos para produção de aglomerados, o que demonstra o potencial para utilização dessas biomassas para produção de painéis reconstituídos, visto que painéis com baixa densidade utilizam maior número de partículas para se ter um mesmo volume compactado, aumentando, assim, a razão de compactação, que influencia em uma melhor qualidade das propriedades físico-mecânicas.

Para os extrativos totais, observaram-se valores médios de 5,04\% para eucalipto e $14,55 \%$ para resíduo de sorgo. Os valores encontrados para esse componente químico presente no sorgo é superior ao observado por Protásio et al. (2012), que trabalharam com diferentes materiais lignocelulósicos, como casca de arroz (4,03\%) e casca de café $(8,60 \%)$; e Scatolino et al. (2013), estudando resíduo do milho $(5,2 \%)$. Para a madeira de eucalipto, os valores foram próximos aos encontrados por Lima et al. (2007) em clones de Eucalyptus urophylla $(5,17 \%)$.

De acordo com Pettersen (1984), os extrativos podem constituir até $8 \%$ do peso seco de madeiras de espécies

Pesq. flor. bras., Colombo, v. 36, n. 88, p. 435-442, out./dez. 2016 
comuns de clima temperado, podendo chegar a até $20 \%$ em madeiras em espécies tropicais. Segundo Iwakiri (2005), quanto maior o valor de extrativos totais em matérias-primas lignocelulósicas, maiores possibilidades destas não gerarem painéis reconstituídos de boa qualidade, em função de problemas de consumo de adesivos, diminuição da resistência mecânica e absorção de água, além de ocorrência de bolhas de ar durante a prensagem. Neste sentido, os materiais lignocelulósicos estudados apresentaram-se dentro do intervalo esperado e com baixos percentuais de extrativos, sendo indicativo do seu potencial de uso para painéis aglomerados.

\section{Propriedades físicas dos painéis aglomerados}

Não houve efeito significativo da adição de bagaço de sorgo nos painéis (Figura 1). Observa-se que estes variaram entre 0,44 e $0,48 \mathrm{~g} \mathrm{~cm}^{-3}$. Portanto, os painéis são classificados como de baixa densidade, de acordo com Iwakiri (2005). As densidades aparentes médias dos painéis também diferiram da densidade nominal estipulada de $0,60 \mathrm{~g} \mathrm{~cm}^{-3}$. Fato que pode ser justificado devido à perda de partículas durante a formação do colchão, e que também pode estar relacionado ao retorno em espessura dos painéis, após a retirada da prensa quente e acondicionamento, com consequente aumento do volume dos painéis e redução da densidade nominal inicial.

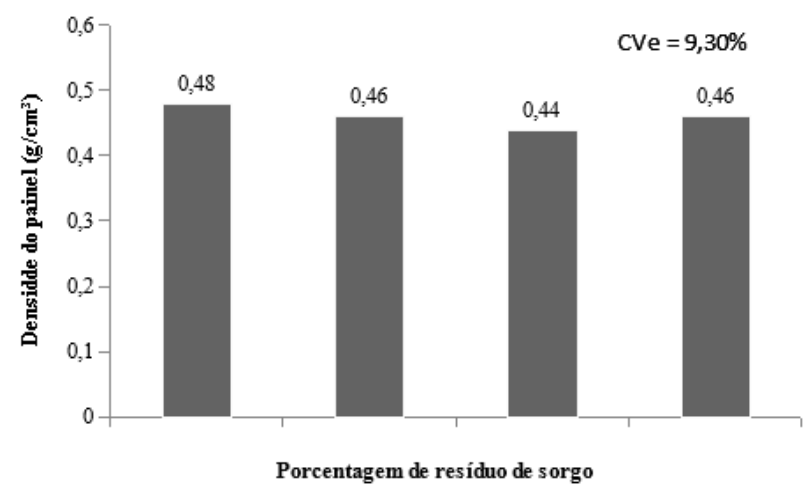

Figura 1. Densidade nominal dos painéis aglomerados. Médias seguidas de mesma letra não diferem significativamente pelo teste Scott-Knott com um nível de significância de 5\%. CVe = coeficiente de variação experimental.

Na Figura 2 estão apresentados os valores de razão de compactação para os painéis aglomerados produzidos com madeira de eucalipto e resíduos de sorgo. Observase que, com aumento da inserção de resíduos de sorgo, há um aumento linear da razão de compactação; sendo que a cada $1 \%$ de inserção de sorgo no painel ocorre um aumento na razão de compactação na ordem de aproximadamente 0,0059 .

Tais resultados se devem à baixa densidade do material sorgo $\left(0,16 \mathrm{~g} \mathrm{~cm}^{-3}\right)$ em comparação com a madeira de eucalipto $\left(0,39 \mathrm{~g} \mathrm{~cm}^{-3}\right)$. Como a razão de compactação é determinada pela relação entre a densidade do painel e a densidade do material lignocelulósico, tal valor aumenta conforme é adicionada maior porcentagem de sorgo na associação com madeira.

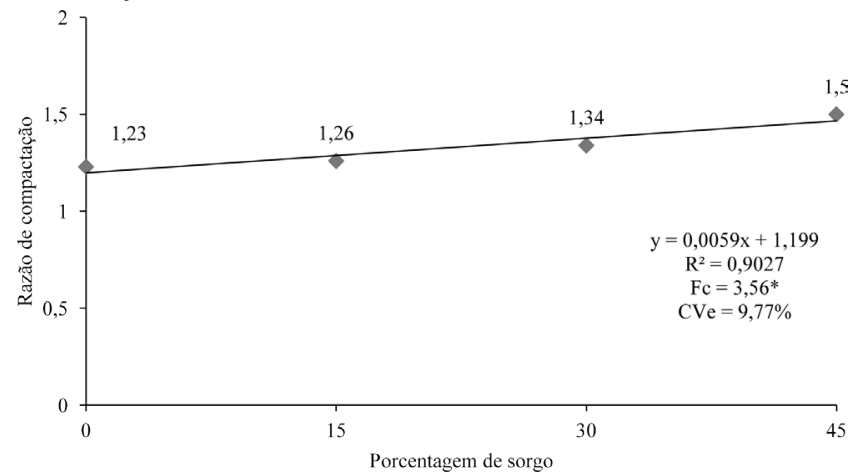

Figura 2. Razão de compactação dos painéis aglomerados, ${ }^{*}$ valor estatisticamente significativo ao nível de $5 \%$ de significância. $\mathrm{CVe}=$ coeficiente de variação experimental.

Maloney (1993) e Tsoumis (1991) estabelecem que a faixa ideal de razão de compactação é entre 1,3 a 1,6. Neste sentido, os tratamentos que se apresentaram dentro deste intervalo foram de 30 e $45 \%$ de sorgo.

Os valores de absorção de água após 2 e 24 h de imersão em água nos painéis, com diferentes porcentagens de sorgo, podem ser visualizados nas Figuras 3 e 4, respectivamente. A regressão linear foi a que melhor representou a relação entre a porcentagem de sorgo no painel e a absorção de água, sendo estatisticamente significativa. Observa-se que o aumento na inserção de sorgo no painel, na ordem de $1 \%$, proporciona elevação de 1,4771 e 1,6061\% de absorção de água, após 2 e 24 $\mathrm{h}$ de imersão, respectivamente. Isso pode ser justificado pelo aumento da razão de compactação dos painéis, pois aqueles produzidos com maiores quantidades de resíduos de sorgo apresentaram aumento desta propriedade, o que leva a um maior número de partículas compactadas em um mesmo volume e, consequentemente, maiores exposição de sítios hidroxílicos, o que pode levar a uma maior afinidade deste material com a água.

Mendes et al. (2010a), trabalhando com casca de café para produção de painéis aglomerado, não observaram relação entre a inserção deste resíduo no painel e absorção de água, após $2 \mathrm{~h}$ de imersão. Porém, após 
$24 \mathrm{~h}$ os autores observaram um comportamento linear crescente de absorção de água com o aumento da adição de casca de café na produção de painéis aglomerados, sendo que os valores para essa propriedade oscilaram entre 70 e 95\%. Por outro lado, Mendes et al. (2010b), trabalhando com bagaço de cana para produção de painéis aglomerados, verificaram após $2 \mathrm{~h}$ que o aumento de resíduos promovia uma melhora na absorção de água, enquanto que após $24 \mathrm{~h}$ de imersão os autores não notaram efeito da adição de bagaço de cana na propriedade física estudada.

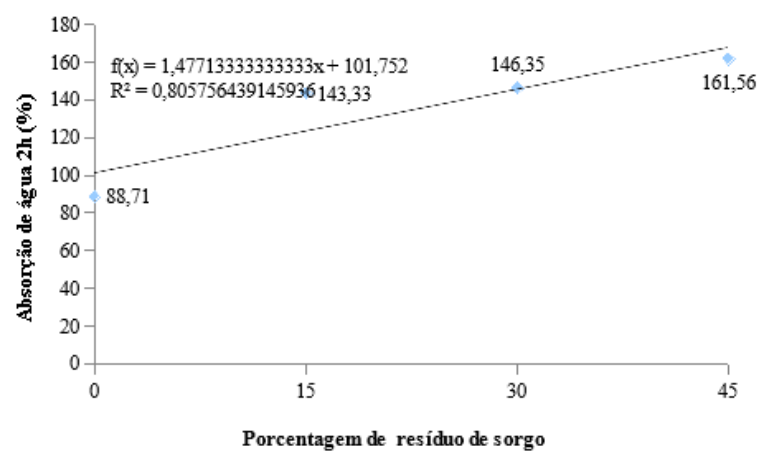

Figura 3. Absorção de água dos painéis após $2 \mathrm{~h}$ de imersão em água dos painéis aglomerados. *valores estatisticamente significativos ao nível de $5 \%$ de significância. CVe $=$ coeficiente de variação experimental.

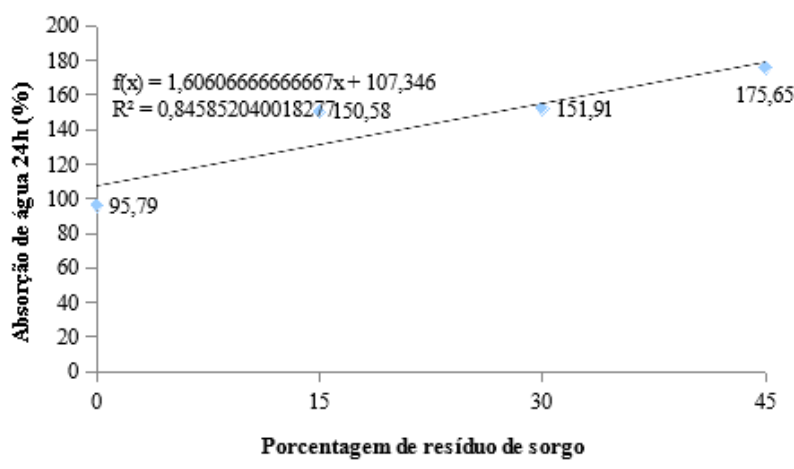

Figura 4. Absorção de água dos painéis após $24 \mathrm{~h}$ de imersão em água dos painéis aglomerados. *valores estatisticamente significativos ao nível de $5 \%$ de significância. $\mathrm{CVe}=$ coeficiente de variação experimental.

Carvalho et al. (2014), trabalhando com painéis aglomerados de baixa densidade, com inserção de adesivos tanínicos, notaram que a absorção de água após $2 \mathrm{~h}$ de imersão variava entre 80,7 e 95,4\%. Após 24 h de imersão os autores observaram valores entre 90,5 e $108 \%$. Neste sentido, os tratamentos com inserção de sorgo nos painéis apresentaram valores acima dos referenciados em literatura. Esses resultados podem ser explicados, pois os painéis deste trabalho não foram produzidos com aplicação de emulsão de parafina, que é um agente que diminui a afinidade da chapa com a água.

Os valores médios obtidos para as propriedades de inchamento em espessura, após $2 \mathrm{~h}$ (IE2h) e 24 h (IE24h) de imersão em água, estão apresentados nas Figuras 5 e 6 , respectivamente. Os resultados mostram que não existe efeito significativo para as porcentagens de sorgo associadas à madeira de eucalipto para IE2h e IE24h. Diferentemente, Scatolino et al. (2013) trabalhando com inserção de sabugo de milho na produção de painéis aglomerados, na ordem de 0, 25, 50, 75 e 100\% do painel, observou efeito negativo do incremento de resíduo no IE2h e IE24h. Os autores encontraram valores para inchamento em espessura próximos aos observados neste trabalho, com IE2h variando entre 19,06 e 25,8\% e IE24h com valores de 31,79 a 37,94\%.

Quando comparados com trabalho realizado por Melo et al. (2009), ao avaliarem diferentes porcentagens de casca de arroz adicionadas à madeira de eucalipto para produção de painéis aglomerados, os autores encontraram valores de IE2h variando entre 9\% e 17\%, sendo estes inferiores ao observado neste trabalho. Para IE24h os autores encontraram valores superiores aos observados para os painéis de sorgo, com valores entre 45 a $49 \%$.

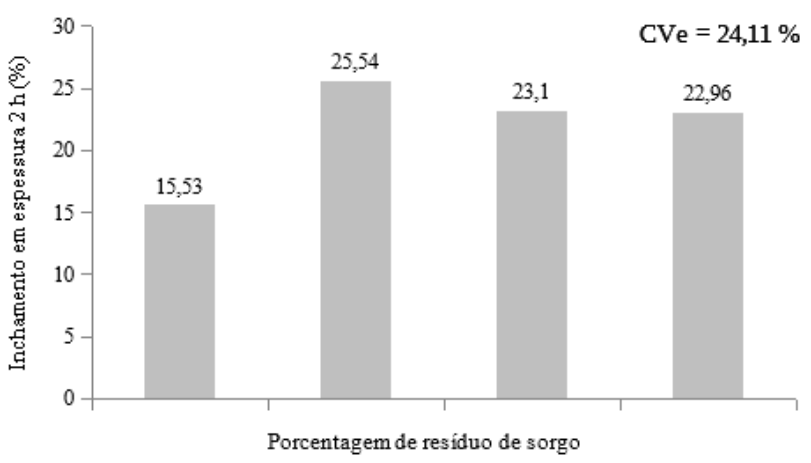

Figura 5. Inchamento em espessura após 2 h de imersão em água dos painéis aglomerados. Médias seguidas de mesma letra não diferem entre si pelo teste Scott-Knott com um nível de significância de 5\%. CVe = coeficiente de variação experimental. 


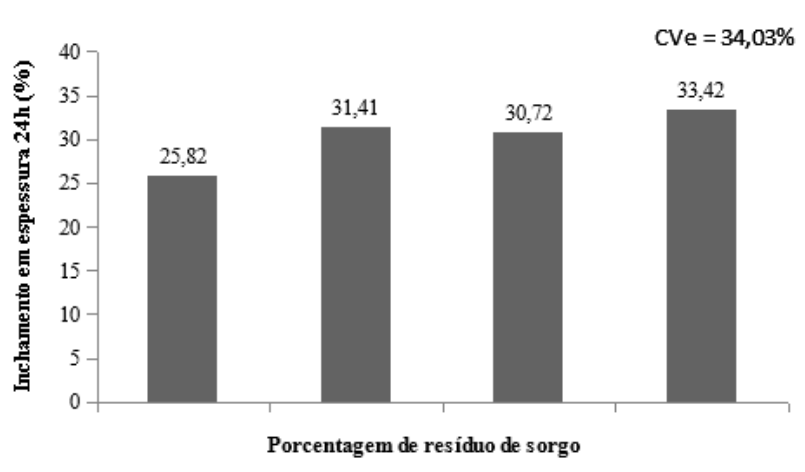

Figura 6. Inchamento em espessura após 24 h de imersão em água dos painéis aglomerados. Médias seguidas de mesma letra não diferem entre si pelo teste Scott-Knott com um nível de significância de $5 \%$. CVe $=$ coeficiente de variação experimental.

Como não houve diferença estatística significativa entre os tratamentos, observou-se que o valor médio para IE24h foi de 30,34\%. A norma CS 236-66 (Commercial Standard, 1968) estabelece valor máximo de IE24h de $30 \%$. Neste sentido, de maneira geral, pode-se dizer que os painéis apresentaram uma diferença de 1,13\% acima da média, estando muito próximos das exigências normativas.

\section{Propriedades mecânicas dos painéis aglomerados}

Na Figura 7 verifica-se o comportamento da tração perpendicular nos painéis aglomerados. A regressão linear foi a que melhor representou a relação entre porcentagem de sorgo e os valores de tração perpendicular, sendo que houve uma correlação significativa e negativa, ou seja, houve redução dos valores médios desta propriedade com elevação da proporção de sorgo no painel.

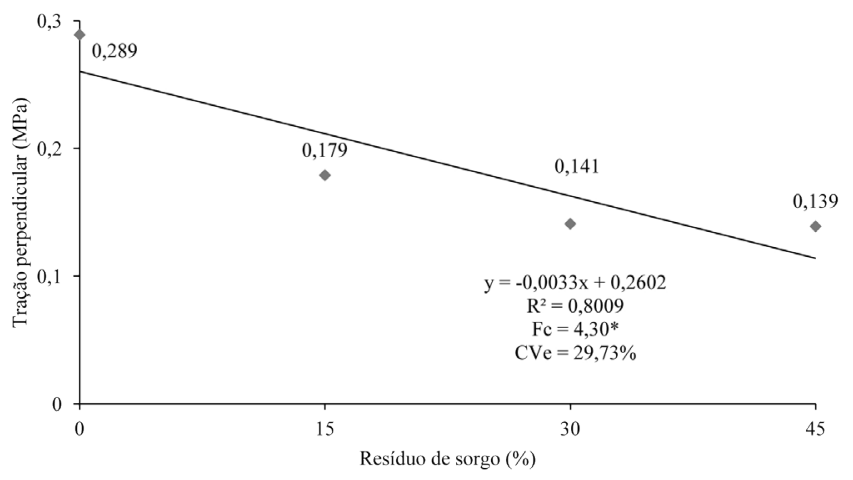

Figura 7. Tração perpendicular para os painéis aglomerados convencionais, ${ }^{*}$ valor estatisticamente significativo ao nível de 5\% de significância. CVe = coeficiente de variação experimental.
Essa tendência de decréscimo também foi observada por Mendes et al. (2010a), quando avaliaram os valores de ligação interna em função do aumento das porcentagens de casca de café $(25,50$ e $75 \%)$, em painéis aglomerados de Eucalyptus urophylla. Os valores de ligação interna decresceram de $0,30 \mathrm{MPa}$ a $0,15 \mathrm{MPa}$ conforme se aumentava a porcentagem de casca de café.

A tração perpendicular é uma propriedade que avalia a relação de colagem entre as partículas. Neste sentido, o comportamento visualizado na Figura 5 pode ser explicado pelo aumento do teor de extrativos nos painéis, com o aumento da inserção de resíduos de sorgo. Marra (1992) afirma que materiais lignocelulósicos com elevados teores de extrativos apresentam dificuldades de colagem, resultando em baixa resistência da ligação adesiva entre as partículas. Outro fator a qual esse resultado pode ser atribuído é a baixa densidade dos resíduos, pois o aumento no número de partículas acarreta em menor disponibilidade de adesivo por partícula, o que prejudica a colagem.

A norma de comercialização CS 236-66 estabelece valor mínimo de 0,14 MPa para tração perpendicular nos painéis de baixa densidade e produzidos com adesivo ureia formaldeído. Neste sentido, igualando-se o valor de norma à equação observada na regressão linear, nota-se que a inserção máxima de sorgo no painel, para atendimento das exigências normativas, é de $36,42 \%$.

O comportamento do módulo de elasticidade (MOE) nos painéis produzidos com diferentes teores de sorgo pode ser visualizado na Figura 8. Percebe-se que o aumento em $1 \%$ da proporção de resíduo no painel promove decréscimo dessa propriedade mecânica em 8,1298 MPa.

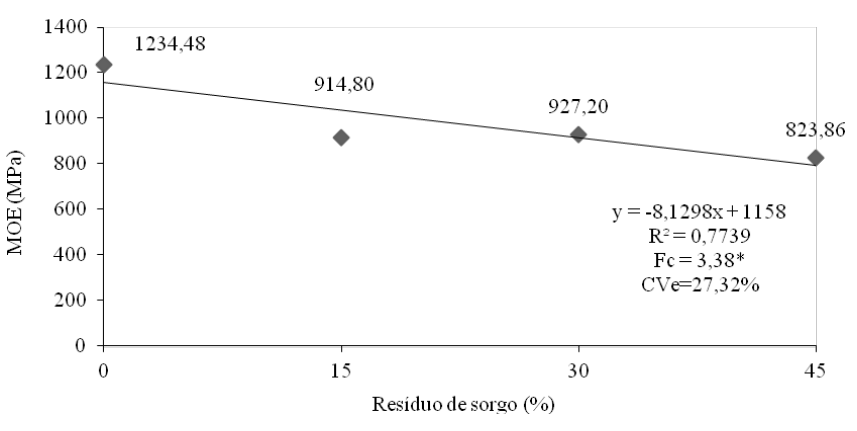

Figura 8. Módulo de elasticidade em flexão estática para os painéis aglomerados, ${ }^{*}$ valor estatisticamente significativo ao nível de $5 \%$ de significância. $\mathrm{CVe}=$ coeficiente de variação experimental. 
Ferreira (2013), em trabalho realizado com resíduo de casca noz macadâmia para produção de painéis em diferentes proporções, concluiu que a diminuição do MOE com aumento da inserção de resíduo pode ser justificada pelo fato destes resíduos lignocelulósicos apresentarem menor plasticidade que a madeira, ou seja, são mais elásticos e menos rígidos, o que pode levar a uma colagem de menor qualidade, influenciando a capacidade de deformação do material, ou seja, ele suporta menor deformação elástica, devido ao fato de que esta deformação não pode ser distribuída uniformemente dentro do material, já que este possui maior quantidade de espaços vazios, a medida que aumenta a quantidade de partículas de resíduos.

Battistelle et al. (2009), trabalhando com painéis de resíduo de bagaço de cana, nas proporções de 0,25 , 50,75 e $100 \%$, sendo reforçado com folhas de bambu, observaram comportamento similar a este trabalho, com decréscimo de MOE a medida que aumentavam a inserção de resíduos de cana. Estes autores encontraram valores para essa propriedade variando entre 998 e 1.662 $\mathrm{MPa}$, valores pouco acima dos observados neste estudo. Contudo, cabe ressaltar que os painéis produzidos por estes autores foram de média densidade, enquanto os deste estudo foram de baixa densidade, fator esse que pode influenciar significativamente nessa propriedade.

A norma de comercialização CS 236-66 (Commercial Standard, 1968) estabelece, como valor mínimo para painéis de baixa densidade e adesivo ureia formaldeído, o valor de $1.052 \mathrm{MPa}$ para MOE. Quando se iguala o valor normatizado na regressão linear gerada para essa propriedade, observa-se que o ponto limite de inserção de sorgo no painel, para atendimento às exigências normativas, é de 13,04\%.

O modelo de regressão ajustado em função do aumento da porcentagem de sorgo para os valores de módulo de ruptura (MOR) e flexão estática está representado na Figura 9. Observa-se que o aumento de $1 \%$ de resíduo, levou a um decréscimo de MOR na ordem de 0,0558 MPa.

A diminuição de valor de MOR à medida que se aumenta a inserção de sorgo pode ser devido à razão de compactação. Moslemi (1974) e Maloney (1993) ressaltam que maiores razões de compactação podem levar à elevação da área superficial específica das partículas. Nessas condições, a aplicação do mesmo conteúdo de adesivo diminui a sua disponibilidade por unidade de área superficial das partículas, podendo resultar em painéis com menores valores nas propriedades mecânicas

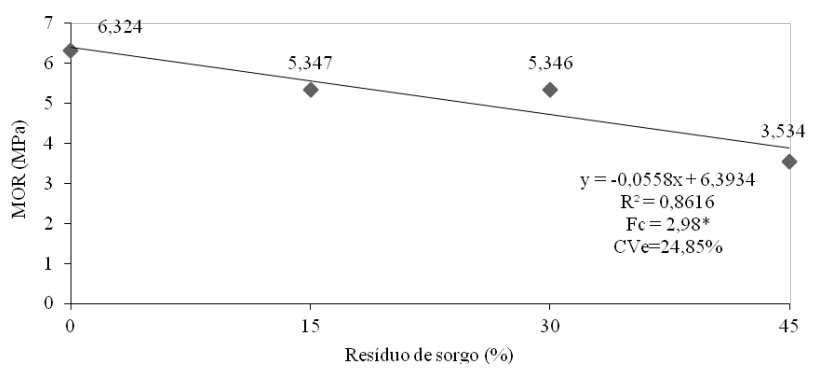

Figura 9. Módulo de ruptura em flexão estática para os painéis. *valor estatisticamente significativo ao nível de 5\% de significância. $\mathrm{CVe}=$ coeficiente de variação experimental.

Mendes et al. (2010a), trabalhando com casca de café nas proporções de 25, 50 e $75 \%$, para produção de aglomerados, notaram tendência similar à observada neste trabalho, com valores oscilando entre 1,94 e 7,49 MPa. Neste sentido, cabe ressaltar que os painéis produzidos por aqueles autores apresentavam média densidade, enquanto que os deste estudo são de baixa densidade

De acordo com a norma de comercialização CS 236-66 (Commercial Standard, 1968), os painéis aglomerados produzidos com adesivo ureia formaldeído e de baixa densidade, devem apresentar, no mínimo, resistência à flexão estática de 5,6 MPa. Neste sentido, igualando-se a equação estimativa de MOR com o valor de exigência de norma, verifica-se o atendimento a mesma até a inserção máxima de sorgo de $14,21 \%$.

\section{Conclusões}

De maneira geral, os painéis produzidos com resíduo de sorgo apresentam viabilidade técnica de produção, quando adicionado aproximadamente $13 \%$ de resíduo.

Os painéis confeccionados com resíduo de sorgo apresentaram densidade inferior à nominal.

A cada $1 \%$ de sorgo acrescentado nos painéis houve um aumento de 1,4771 e 1,6061\% na absorção de água a 2 e 24 h de imersão, respectivamente. No entanto, não houve efeito significativo com aumento da porcentagem de sorgo nas propriedades físicas, apresentando valor médio de IE24h apenas de 1,13\% maior que o exigido pela norma CS 236-66.

A tração perpendicular apresentou comportamento linear decrescente com aumento da inserção de sorgo na chapa. A quantidade máxima de resíduos aplicados 
ao painel para atendimento a CS 236-66 deve ser de $36,42 \%$.

Para cada $1 \%$ de sorgo no painel houve um decréscimo em 8,1298 Mpa do módulo de elasticidade (MOE) e 0,0558 Mpa do módulo de ruptura (MOR). O valor máximo de adição de sorgo nos painéis para atender as exigências da norma CS 236-66 deve ser de 13,04 e $14,21 \%$ respectivamente, para MOE e MOR.

Para as propriedades mecânicas houve decréscimo com aumento da porcentagem de sorgo, sendo que a quantidade máxima de resíduos inserido no painel para atendimento da CS (Commercial Standard, 1968) foi de $13,04 \%$.

\section{Referências}

Associação Brasileira de Normas Técnicas. NBR 11941: madeira: determinação da densidade básica. Rio de Janeiro, 2003.

Associação Brasileira de Normas Técnicas. NBR 7987 T 204 om-88: madeira: determinação dos teores de extrativos. Rio de Janeiro, 1998.

Battistelli, R. A. G. et al. Emprego do bagaço da cana-de açúcar (saccharum officinarum) e das folhas caulinares do bambu da espécie dendrocalamus giganteus na produção de chapas de partículas. Revista Minerva, v. 5, n. 3, p. 297-305, 2009.

Carvalho, A. G. et al. Adesivos tânicos de Stryphnodendron adstringens (Mart.) Coville na produção de painéis aglomerados. Revista Árvore, v. 38, n. 1, 2014. DOI: 10.1590/S010067622014000100019.

Commercial Standard. CS 236-66: mat formed wood particleboard. [S.1.], 1968

Companhia Nacional de Abastecimento (Brasília, DF). Acompanhamento da safra brasileira de grãos: v. 2: Safra 2014/15: oitavo levantamento. Brasília, DF, 2016.

Eggleston, G. et al. New commercially viable processing technologies for the production of sugar feedstocks from sweet sorghum (Sorghum bicolor L. Moench) for manufacture of biofuels and bioproducts. Sugar Tech, v. 15, n. 3, p. 232-249. 2013. DOI: 10.1007/s12355013-0229-6.

Ferreira, B. S. Propriedades físico-mecânicas de painéis particulados de Eucalyptus saligna e casca de noz macadâmia. 2013. 78 f. Dissertação (Mestrado em Engenharia Mecânica) - Universidade Estadual Paulista Júlio de Mesquita Filho, Guaratinguetá.
Guimarães Junior, J. B. et al. Painéis de madeira aglomerada de resíduos da laminação de diferentes procedências de Eucalyptus grandis, Eucalyptus saligna e Eucalyptus cloeziana. Cerne, v. 17, n. 4, p. 443-452, 2011. DOI: 10.1590/S0104-77602011000400002. Instituto de Pesquisas Tecnológicas (São Paulo). Fichas de características das madeiras brasileiras. 2. ed. São Paulo, 1989. $418 \mathrm{p}$.

Iwakiri, S. Painéis de madeira reconstituída. Curitiba: FUPEF, 2005. 274 p.

Lima, C. K. P. et al. Características anatômicas e química da madeira de clones de Eucalyptus e sua influência na colagem. Cerne, v. 13, n. 2, p. 123-129, 2007.

Maloney, T. M. Modem particleboard and dryprocess fibeboard manufacturing. 2. ed. São Francisco: M. Freeman, 1993. 689 p.

Marra, A. A. Technology of wood bonding. New York: Van Nostrand Reinhold, 1992. 453 p.

Melo, R. R. et al. Propriedades físico-mecânicas de painéis aglomeradas produzidos com diferentes proporções de madeira e casca de arroz. Ciência Florestal, v. 19, n. 4, p. 449-460, 2009.

Mendes, R. F. et al. Efeito da incorporação de casca de café nas propriedades físico-mecânicas de painéis aglomerados de Eucalyptus urophylla S. T. Blake. Ciência e Agrotecnologia, v. 34, n. 3, 2010 a. DOI: $10.1590 / \mathrm{S} 1413-70542010000300012$.

Mendes, R. F. et al. Painéis aglomerados produzidos com bagaço de cana em associação com madeira de eucalipto. Scientia Forestalis, v. 38 , n. 86 , p. $285-295,2010$ b.

Moslemi, A. A. Particleboard. Carbondale: Sothern Illinois University Press, 1974. 244 p.

Mussatto, S. I. et al. Technological trends, global market, and challenges ofbio-ethanol production. Biotechnology Advances, v. 28, p. 817-830, 2010. DOI: 10.1016/j.biotechadv.2010.07.001.

Pettersen, R. C. The chemical composition of wood. In: Rowell, R. (Ed.). The chemistry of solid wood. Washington, DC: American Chemical Society, 1984. p. 54-126.

Protásio, T. P. et al. Correlações canônicas entre as características químicas e energéticas de resíduos lignocelulósicos. Cerne, v. 18, n. 3, p. 433-439, 2012. DOI: 10.1590/S0104-77602012000300010.

Scatolino, M. V. et al. Uso do sabugo de milho na produção de painéis aglomerados. Ciência e Agrotecnologia, v. 37, n. 4, p. 330-337, 2013. DOI: $10.1590 / \mathrm{S} 1413-70542013000400006$.

Tsoumis, G. Science and technology of wood: structure, properties and utilization. New York: Chapman \& Hall, 1991. 494 p. 